\title{
Conditions for building a community of practice in an advanced physics laboratory
}

\author{
Paul W. Irving and Eleanor C. Sayre \\ Department of Physics, Kansas State University, Manhattan, Kansas 66506, USA
}

(Received 6 December 2013; published 17 March 2014)

\begin{abstract}
We use the theory of communities of practice and the concept of accountable disciplinary knowledge to describe how a learning community develops in the context of an upper-division physics laboratory course. The change in accountable disciplinary knowledge motivates students' enculturation into a community of practice. The enculturation process is facilitated by four specific structural features of the course and supported by a primary instructional choice. The four structural features are "paucity of instructor time," "all in a room together," "long and difficult experiments," and "same experiments at different times." The instructional choice is the encouragement of the sharing and development of knowledge and understanding by the instructor. The combination of the instructional choice and structural features promotes the development of the learning community in which students engage in authentic practices of a physicist. This results in a classroom community that can provide students with the opportunity to have an accelerated trajectory towards being a more central participant of the community of a practice of physicists. We support our claims with video-based observations of laboratory classroom interactions and individual, semistructured interviews with students about their laboratory experiences and physics identity.
\end{abstract}

DOI: 10.1103/PhysRevSTPER.10.010109

PACS numbers: 01.40.G-, 01.55.+b

\section{INTRODUCTION}

The development of a professional identity is a fundamental part of student development [1]. An appropriate subject-specific identity is a strong influence on students' persistence in a discipline [2-5]. There is a strong relationship between the development of a professional, subject-specific identity and participation in a related community [6-8]; in fact, professional identity and community participation are inextricably and symbiotically linked [8-10].

Laboratory work, in particular, is generally seen as an opportunity for students to learn problem solving and develop their understanding of physics as well as to understand how the community of practicing physics works and to eventually be able to take part in this community themselves [11].

In this paper, we claim that structural and programmatic features of a junior-level Advanced Laboratory course ("AdLab") at Kansas State University, supported by instructor strategies, promote students' enculturation into the community of practicing physicists by fostering a classroom learning community engaged in bench research. We support our claims with ethnographic interviews and with observations of AdLab students.

Published by the American Physical Society under the terms of the Creative Commons Attribution 3.0 License. Further distribution of this work must maintain attribution to the author(s) and the published article's title, journal citation, and DOI.

\section{COMMUNITIES OF PRACTICE FRAMEWORK}

We use a communities of practice framework to describe how students develop a classroom community in AdLab. Communities of practice have three key characteristics: the individuals within form a group, either colocated or distributed $[12,13]$, the group has common goals or shared enterprise [12,14], and the group shares and develops knowledge focused on a common practice [12,14]. This final characteristic can be extended to include the sharing of mutually defined practices, beliefs, values, and history.

An individual participates in several overlapping communities of practice. A physics student involved in a research group might also be the goalie on a sports team, for example. That same research group might be part of a larger collaboration and, at the same time, members of the research group are also members of the physics department. Because one individual participates in several overlapping communities, it is important to study how "more expansive networks" [7,15] affect individuals' participation. Active participants in different communities of practice have opportunities to learn the knowledge, rituals, and histories valued within each community [8,16-18]. Inasmuch as the different communities overlap, knowledge and practices learned in one community affects practices in another $[10,19,20]$. Conversely, when communities have different values, individual members may have difficulty importing practices from one community to another $[21,22]$.

In this paper, we are primarily concerned with two overlapping communities: the classroom community which develops within AdLab and the generalized community of practicing physicists to which students are aspiring 
members. These two communities share many goals and norms: AdLab is part of students' training to become physicists and some (but not all) of the practices in AdLab are common to the professional practice of physics. Of course, the students in these two communities are also members of other communities, but we do not focus on those aspects of their identity in this paper.

\section{A. Duration}

Frequently, communities of practice evolve and grow for extended periods [12] and may involve many participants over time. In these communities, newcomers are socialized into the community of practice through mutual engagement with and support of old-timers. Through low-level but authentic practices, these peripheral participants are slowly inducted into the knowledge and skills of a particular practice. Over time, they develop more understanding, knowledge, and skills, becoming central participants and eventually mentoring their own peripheral participants $[8,14]$.

Students in the process of moving from being a peripheral participant to a central participant are referred to as having a trajectory towards being a central member of a community. Being on a trajectory within a community of practice is generally considered a slow induction process [8]. In the AdLab course students are exposed to a greater number of the authentic practices of members of the community of practice of physicists. We believe that different classroom communities of practice provide different levels of authentic practice and, therefore, the opportunity for students to accelerate their own trajectory towards becoming a central member of a discipline-based community (both the broader community of physics undergrads and the community of practicing physicists).

Other communities of practice have shorter duration, such as the length of a semester, and may have fewer members. Classrooms as communities of practice are well studied [23-26]. In these shorter-term, temporally bounded communities [27], we discard the idea of newcomers and old-timers in favor of the more general idea of peripheral and central participants. Legitimate peripheral participants may sit on the outskirts of classroom discussion, learning discourse and norms [28] as they gradually become enculturated [10]. Conversely, central participants may speak frequently in discussion, be more active in setting norms, or interact with more participants.

\section{B. Learning}

Learning physics is a primary objective in a physics classroom. In a community of practice, learning can be conceptualized using situated cognition [11], participation theory $[29,30]$, and socially constructed knowledge or understanding [8,31], or as a process of becoming a member of a community [17,18]. Under these models, learning physics is not merely about learning the contents of physics textbooks, but also about learning ways to participate in the cultural enterprise of professional physicists. Another way of examining this shift to viewing physics as an enculturation process is to discuss accountable disciplinary knowledge (ADK) [32].

ADK can be described as "what counts" as doing physics: the kinds of activities, problems, and discourse that people engage in when they are participating in any physics community of practice whether it be a classroom community, the broader community of physics undergrads, or the community of practicing physicists. For example, from our experience, doing well at the introductory physics level often entails solving 15 end-of-chapter problems weekly in a few hours alone, and doing well at the upper-division undergraduate level entails solving a few problems weekly in 15 hours with peers. This difference in "what counts" as doing physics well constitutes a substantial change in accountable disciplinary knowledge between introductory and upper-division physics. Students who do not adjust their sense of what "doing well" entails may feel that they are no longer good at physics when they reach the upper division. As students progress in their undergraduate career and enter different classroom communities, the ADK in each classroom will be different. In the context of both the broader community of undergrads and the community of practicing physics, the substantial change in ADK from an introductory course to the advanced lab course relates to the legitimate peripheral practices becoming more central practices.

\section{Tension between scientist and classroom practices}

If courses like AdLab are to prepare students to be physicists - to become more central participants in the community of practicing physicists - then those students should engage in legitimate peripheral activities in the community of practicing physicists. Though physics classrooms and the larger physicist community share many of the same norms and practices, they differ in several key respects [33-36]. For example, traditional teaching laboratories tend to emphasize reproducing prior results rather than creating new knowledge [37]. Introductory physics classes tend to promote students solving many problems weekly while professional physicists work in large teams over multiple years to solve single problems.

To counteract this disconnect between school science practices and professional ones, the teacher can take on the role of a broker, acting as a go-between between the classroom community and the community of practicing physicists. They take on the role of guiding the classroom community closer to that of the practicing physics community. A teacher can promote classroom norms and allow activities that are legitimate activities of physicists [38]. More advanced coursework is more likely to enact norms and practices that are more like those in the larger professional community of physicists, as many faculty 
are more likely to treat advanced students as junior physicists.

\section{INSTRUCTIONAL CONTEXT}

At Kansas State University, AdLab is traditionally taken by sophomores and juniors, both physics majors and physics minors. It meets twice weekly for three hours each meeting; experiments usually take two to three weeks to complete. Class time is almost entirely devoted to laboratory work, with student presentations once during the semester. The students produce an individual laboratory report for each experiment. The experiments include common topics in modern physics such as the "lifetime of the $\mu$ meson" and "microwave optics." Like many upperlevel laboratory classes, each experimental setup has only one set of equipment. Students rotate through the experiments, and each student will perform a subset of the total number of experiments available.

The advanced laboratory is described as follows in the course catalog: "The completion of experiments of current and/or historical interest in contemporary physics. Students develop skills in and knowledge of measurement techniques using digital and analog instruments. Various data analysis techniques are used."

There were 18 students enrolled in the lab at the beginning of the semester and 17 finished the semester; students were organized into six groups. Group members stayed together for the first three experiments and then some members switched for the final three experiments. The switch was instigated by the instructor. One group remained consistent due to a significant delay in finishing one of their experiments and so were out of synchronization with the rest of the laboratory groups.

\section{A. Structural and instructional features}

Within AdLab, there are several structural and instructional features that result in the development of a classroom community. We find four structural features:

Paucity of instructor time.-There are six groups working on six different experiments, each of which is complicated and prone to conceptual, experimental, or equipment difficulties. There is one instructor. The instructor simply does not have enough time to spend with each group. When students need help, they must frequently turn to other sources.

All in the room together.-All groups work in the same room at the same time. Because they are in close proximity to each other, there are more chances for interaction between groups.

Long and difficult experiments.-The experiments last two or three weeks, and involve complicated and sometimes finicky equipment, difficult error propagation techniques, or conceptual complexity. This has two implications for community formation: students need to seek out resources to help with troubleshooting their own experiments and (at any given time) they have time available to help their peers troubleshoot a different experiment.

Same experiments at different times.-Because groups cycle through experiments, pockets of localized expertise develop. When a new group starts on an experiment, the last group to perform that experiment has direct, localized expertise about performing it.

Additionally, we find one primary instructional choice that supports the development of a classroom community of practice within AdLab. The instructor of the class, recognizing the structural constraints above, deliberately encourages the sharing and developing of knowledge and understanding between lab groups.

\section{B. Elements of classroom community}

These four structural features, supported by the instructional choice, work in concert to promote the development of a classroom community of practice. This classroom community of practice has several elements as a result of the structural features and the instructional choice that are not typical of a classroom community. We will refer to these elements as enculturation elements as these elements encourage some of the authentic practices of physicists. The elements described below emerged from ethnographic analysis of our data AdLab learning environment. These elements emerged as themes from the data and are necessary but not sufficient for the development of the classroom community within the learning environment. Other necessary elements may include the following: the students purpose in taking the class and a shared primary language, but these elements either did not emerge from the data or we were unable to investigate them from the data collected.

Classroom norms and expectations.- The students have a greater control over the norms that are negotiated within the classroom. These norms are negotiated over time but result in a more collaborative learning environment and in norms that are more similar to those of professional physicists. The same is true for expectations as students expectations of what counts as physics changes over time.

Distributed expertise.-The students become experts in different experiments, which encourages collaboration when groups experience problems with specific experiments.

Community involvement. - The students collaborate and socialize between groups a significant proportion of their time within the AdLab environment.

Many central players. - The socializing and collaboration is not focused on one particular group and is instead distributed throughout all the groups over the length of the AdLab course.

Instructor is not sole mediator.-As the classroom community developed, the students began to perceive the instructor was not the sole mediator of learning.

We believe that all four of the structural features are necessary for these enculturation elements to develop. If 
there were enough instructor time, then students would be more likely to turn to the instructor(s) for help, even if the other three features were present. If the students were not working in the same room at the same time (as happened in the previous laboratory course), the barriers to intergroup interaction would be larger because students would have to seek each other out outside of class and they would not have the equipment in front of them as they discussed the experiments. If the experiments were too simple, the students would not need much help, and if the experiments were too short, they would not have enough time to visit with their colleagues. Finally, if they all performed the same experiment at the same time, they would all develop expertise with particular experiments at about the same rate, so it would be more difficult for more localized pockets to develop. Also, if all groups work on the same experiments at the same time, they are likely to develop similar difficulties at similar times, encouraging the instructors to do mini lectures on specific kinds of troubleshooting and discouraging intergroup discussion.

\section{METHODS}

The research presented in this paper is part of an ongoing ethnographic research project on the identity development of undergraduate physics students.

As a methodology, ethnography originates in anthropology $[39,40]$ and is commonly used to understand community life $[14,41]$. Ethnography is generally concerned with the sociocultural features of an environment, including how people interact and their discursive practices [39,42]. In educational settings, it is used to investigate "classroom culture," characterizing various relationships and events $[42,43]$.

\section{A. Data sources}

Ethnography typically draws its data from a number of sources in order to get a more complete picture of the culture of the classroom and also in an attempt to overcome some of the weaknesses of subjectivity through triangulating multiple viewpoints $[2,6,14,44-46]$. Our data are drawn from diverse sources to triangulate multiple viewpoints on student experiences in Adlab.

The primary data set for this analysis comes from observations of students participating in AdLab. Lab groups of three students were observed twice a week for three hour class sessions. The observations were systematic and as complete as possible with the equipment available to the research team. Four groups were recorded every week and only a small percentage of the data were lost due to technical issues. This paper focuses on data from the first two weeks of the semester and the last two weeks of the semester. We follow three separate groups at both times. One of the groups (group A) remained the same for the whole semester. Group B changed one member at the

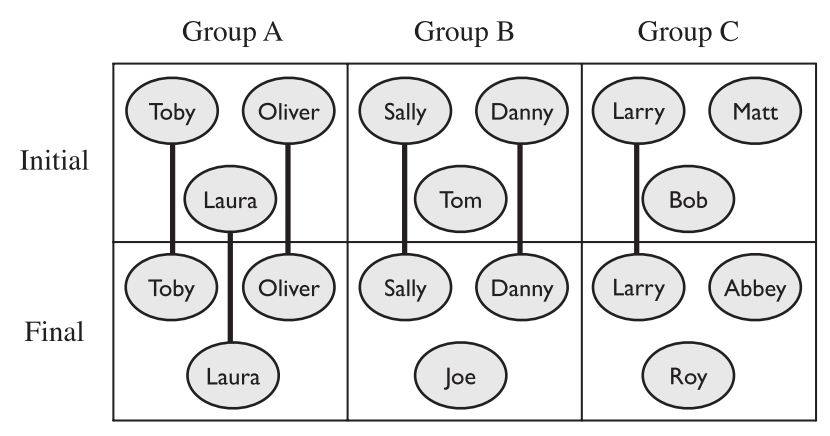

FIG. 1. Group membership at the beginning and at the end of the semester. All names are pseudonyms.

halfway point. In group $\mathrm{C}$, only one group member remained the same. Figure 1 shows group membership and changes over time.

The secondary data set for this paper comes from semistructured interviews with students who were recruited from upper-level physics courses in electromagnetism, mechanics, modern laboratory, and AdLab as part of an ongoing identity study. Only data from AdLab students are included in this analysis, including interviews from before, during, and after their time in the course. We developed a 45-minute semistructured interview protocol drawing on identity formation [6,47], epistemological sophistication $[48,49]$, and metacognition literature [50,51] that also focused on asking the students to describe their AdLab experiences. The interviews were videotaped and transcribed for analysis.

For supporting evidence, we conducted discussions with the course instructor about her goals for the course and how her instructional choices supported them. We also collected course artifacts such as instruction manuals and the syllabus.

\section{B. Analysis methods}

Starting with a macrolevel of analysis, we looked at each class period and referred to our field notes in order to identify "activity segments": all activities whether whole class, particular lab group, or individual that occurred during each laboratory session [52]. With this index of activities we mapped the events of the classroom over time $[52,53]$. This mapping process allowed for analysis on both a topical level and a sequential level and the identification of thematic content.

One theme that emerged from our data was that the different student groups doing separate experiments began to talk to each other more frequently and with higher quality interactions as the course progressed. By higher quality interactions we refer to the interactions that emphasize more of the markers of classroom community development. The students would use their experiment expertise to help another group relate the problem they are encountering with what is going on with the physics of the experiment. 
Another theme that emerged was that both the students and the instructor felt that the physics material and scientific practices in AdLab were closer than previous laboratory classes to ongoing research of practicing physicists. (Other themes emerged. They are not the focus of this paper and will not be discussed here.) We selected these themes for further study and analysis to help us understand how the classroom community of practice develops in the advanced laboratory community and how the AdLab experience affects the professional development of students in the course. It was through this analysis process that the enculturation elements of the AdLab classroom emerged from the data.

The microethnographic analysis began by first identifying interactions between different groups of students. The AdLab room is designed so that the majority of experiments share a table with another experiment or a group is in close proximity (less than $2 \mathrm{~m}$ ) to another group with the exception of the Zeeman experiment which is held in a partitioned area. The cameras were set up typically on the opposite side of the room from the experiment they are recording in order to capture as wide an angle as possible. This setup and the geometry of the AdLab room helped us identify cross-group conversations: while working on a given experiment, a lab group tends to stay clustered around the equipment. We point the camera at the equipment. When a student from another group chats with our group of interest, they tend to physically visit the group of interest.

After all of the interactions had been identified, we began to look at the context and content of the intergroup interactions. We considered the pre- and postcontext of the interaction, student discourse (content, tone of voice, volume of speech, and rhythm of turn taking), and body language of the interaction to interpret how the participants frame the interaction. Framing refers to the resources the students bring to bear for a particular interaction $[54,55]$.

Once the different ways of framing intergroup interactions were identified, we then purposefully sampled specific episodes that represented significant evidence of each type of frame. This analysis of interactions with this microethnographic approach allowed for a correlation to how these interactions related to the development of a community of practice within the advanced laboratory classroom. In order to provide further evidence for our claim that a classroom community of practice developed, we also quantitatively assessed how the number of interactions between groups changed over time and how the amount of time spent having interactions also changed over time.

As we developed the themes and our observational evidence for it, we triangulated and refined the theme using data from the semistructured interviews. Were students aware that a classroom community developed? We also consulted with the instructor to investigate how her instructional goals might shape the course.

\section{OBSERVATIONS OF CLASSROOM COMMUNITY DEVELOPMENT}

The following section focuses on the observational evidence of the classroom community of practice developing in the AdLab learning environment. Through ethnographic analysis of the emerging theme of development of a classroom community of practice, we identified the following episodes that highlight how either the structural features or instructor choices helped this community to form. The episodes were also interpreted to show how the classroom community developed over time from its initiation in the first week. These changes are indicated by the change in negotiated norms and discourse that the students use within the AdLab learning environment.

\section{A. Episode 1: Typical first experiment interaction (the brief me on the experiment interaction)}

This episode occurs during the first week of the AdLab course during each group's first experiment. It is the second day of group C (Larry, Bob, Matt) working on the "E/M Hoag" experiment. This is an experiment that uses a cathode-ray tube to measure the charge-to-mass ratio for an electron by sending electrons down a tube with a known magnetic field supplied by a solenoid. The group struggled on the first day to get the experiment successfully set up to allow for the taking of experimental data, but by the time of this episode on the second day they are just at the point where they are successfully taking data. Carl (from another group) walks by group $\mathrm{C}$ and spots them sitting closely together staring at a screen and decides to ask them how their experiment is going. This episode occurs due to two of the four structural features being in place: all in the room together and same experiments at different times.

Carl What's going on over here?

Bob We're just getting numbers now.

Matt (wearily) Lots of numbers.

Bob (sarcastic tone) Very technical ...

Carl Just looking at that thing, it looks ancient.

Bob (getting more excited) It's funny ... sometimes the voltage will drop by hundreds of volts and to fix it you turn it off and turn it back on (makes a "can you believe this" face). Also this knob broke off so we use a screwdriver to turn it. This knob doesn't even exist anymore!

Carl Nice ... think I'll avoid this one.

This was a very typical interaction at the start of the semester as students took note of what other experiments the different groups where doing and inquired as to the level of difficulty that they involved. The students are aware that they have to do one of the experiments in the room next and because they are all in the room together and are doing the same experiments at different times, it allows them the 
TABLE I. Intergroup interactions at the beginning and at end of the semester. Numbers are percent of total time spent talking to other groups in the second experiment of the semester (Initial) and penultimate lab of the semester (Final).

\begin{tabular}{lccc}
\hline \hline Time period of semester & Group A & Group B & Group C \\
\hline Initial & $1.8 \%$ & $0.9 \%$ & $5.1 \%$ \\
Final & $12.4 \%$ & $8.0 \%$ & $17.3 \%$ \\
\hline \hline
\end{tabular}

opportunity to discuss the different experiments with their colleagues.

The briefness of this exchange is also typical of the first week of the semester. The AdLab community of practice had not fully negotiated the norm associated with the amount of time these inquiries about experiments could last. In the first week these exchanges were all tentative and brief in nature and the students kept to their own group the majority of their time in lab as evidenced by the results in Table I. This is evidence of the initial state of the classroom elements before they are altered due to the structural features of the learning environment. Classroom norms have not been negotiated and expertise has not yet become distributed.

Another regularity of the beginning of the semester was the superficial nature in which Bob talks about the problems with the experiment. His problem is not with the theory behind the experiment or the setting up of the equipment (both of which his group and he had significant trouble with). Instead, his focus is on the machinery being dated and problematic. During the first experiment groups would often have intergroup conversations about the difficulty associated with particular experiments but did so superficially. This could be attributed to the development aspect of the bounded classroom community of practice. The norm for how such conversations should occur had not yet been fully negotiated.

This episode indicates the need for the classroom structural features of all in the room together and same experiments at different times to be present in order for intergroup interactions to occur. These interactions are vital to the development of a classroom community of practice. This episode also indicates that during the first experiment the development process was still occurring and the norms for the classroom community had not yet been negotiated. This is evidence of the initial state of the classroom elements before they are altered due to the structural features of the learning environment.

\section{B. Episode 2: "Brief me on the experiment"}

This episode occurs in week 8 when Larry from group C has now changed groups and is currently working with Abbey and Roy on the microwave optics experiment. It is the last day for all groups on their respective experiments and they are all in the process of deciding what experiment to do next. Liam from another group approaches Larry and asks him about the E/M Hoag experiment which he completed as his first experiment. Essentially, this is a repeat of the "what's going on over here?" interaction that is described in episode 1.

Although the types of interactions progressed from just asking how an experiment is, the "what's going on over here?" interaction continued regularly, but the quality of the interaction increased over time. The focus shifted from an experiment being "easy" or "hard" to "it was interesting" and "this is what we did to overcome the problems and this is the physics beind the experiment." As before, this episode occurs due to the structural features of all in the room together and same experiments at different times, and also long and difficult experiments as students try to preempt troubleshooting before the experiment begins by asking more detailed questions about the experiment to help with their decision making process.

Liam Did you do that one before? (pointing in the direction of a laboratory bench)

Larry The rubidium? (pause) Oh, "E/M Hoag," yeah.

Liam How was that, like for, for theory?

Larry (enthusiastically) Basically I combined the theory and derivation, I just talked about. So, we've got this device ... how can you get a measurement for $\mathrm{E}$ over $\mathrm{M}$ for the solenoid? You know ... for the magnetic field and everything. So in talking about how the field was created inside the solenoid and how that affected the path of the electron ... I felt that covered the theory.

Larry continues to answer several more questions about the experiment before Liam is satisfied with whether he should recommend doing the experiment next to his group.

This episode indicates the change in intergroup interactions as the classroom community norms have been negotiated at this point in the semester. It is now a norm in the community to be more collaborative. Taking time out of one's experiment to have a long detailed discussion with other groups about their or your experiment is common. To inquire about specific details of an experiment is okay, and revealing specific experiment-based expertise to other group members is also okay. Initially, groups were hesitant to talk to each other about the ins and outs of an experiment, but the classroom community of practice evolved into a more collaborative-centered environment once the requisite norms about interacting with other groups had been negotiated.

\section{Episode 3: Instructional choice}

The final episode focuses on the other crucial element present for the AdLab community of practice to develop, 
and that is the instructional choice of the instructor. Toby, Oliver, and Laura are working on the "Millikan oil drop" Experiment as described in episode 4. It is the first session of the new experiment and the instructor comes over to quiz them on how their first tentative steps to setting up the experiment is going. In the Millikan oil drop experiment there is a choice of several oil atomizers that can be employed in the setup of the experiment and this is the focal point of the initial discussions. Because of the structural constraints of the lab at this point in the semester, the instructor is unaware of which atomizer has been working best and invites over a member of the previous group that has carried out the experiment (Tom) to discuss the expertise he has developed with Toby, Oliver, and Laura. It is worth noting that the teaching assistant who set up the experiment in the first place and so has experiment-specific expertise is not called upon to help and instead the group who interacted with the experiment most recently is the one called upon to provide their knowledge of the experiment.

\section{Instructor Did you guys do this last?}

Tom My group did it last (volunteering quickly from other end of room).

Instructor Good, do you have any tips for them?

Tom (Tom walks over) Um, get used to taking it apart and cleaning it.

Instructor Okay, keep cleaning it a lot.

Tom Yeah ... do that a lot. if you get a build up, if there is a big white blotch ... the top which is actually the bottom of the T.V. screen.

Instructor It's labeled top but it says bottom because it's inverted right?

Tom Yeah, if you get a big blotch there you can probably ... it's a build up of oil. You have a little thing to dab it out, dab, and then dab it on a paper towel.

Instructor Use this to dab it out?

Tom Yeah.

Instructor Oh, that's nice. So, you don't have to take it all apart?

Tom Yeah, yeah.

Instructor Okay.

Tom That's an easier way of getting rid of some of the excessive stuff.

Instructor Okay. That's a good tip.

Tom Um, that's about it.

Instructor Okay.

Instructor (enthusiastically) it's fun if you get it to work.

By inviting Tom over, the instructor is sublimely negotiating the norm that it is okay to consult with other groups, especially those who have previously completed the concerned experiment, for help and advice. This encouragement of the development and sharing of knowledge and resources is a deliberate choice by the instructor due to the structural features of the AdLab learning environment. Here, the instructor is negotiating classroom norms: introducing the notion that the students' peers have expertise and the idea that they (the instructor) are not the sole mediator.

\section{Episode 4: Experiment-specific experts}

This episode focuses on the long and difficult experiments structural component. Oliver, Toby, and Laura are working on the Millikan oil drop experiment. For this experiment, the students attempt to measure the charge on the electron by measuring the charge on small oil droplets and conceptualize this charge as a multiple of some quantized charge unit. It is week 8 of the AdLab class and this is the group's second day working on the experiment. Toby has been inputting the results the group has been getting so far into his laptop. Both he and Oliver are confused about how the equation related to the experiment needs to interpreted with their results. They decide to ask for help from Tom, who completed the Millikan oil drop experiment the previous week.

Oliver So, which is the first plate? Is that the bottom here?

Toby Let's ask someone. Hey Tom, I have a question for you (Tom walks over).

Tom This is $d$ and this is the equation here (points at a point on Toby's screen).

Tom proceeds to spend at least the next five minutes explaining his interpretation of their results so far.

As the students began to have a history with experiments, the amount of "can you help me" interactions increased dramatically as evidenced both in the observational data and in the interviews. The students would make reference to not being able to complete a given experiment if it not for another group helping them out at a critical juncture. The helping of other students is a clear indication of a classroom community developing with students building up experiment-centric expertise and then sharing this expertise due to all of the highlighted structural features of the learning environment but especially paucity of instructor time and long and difficult experiments. At the beginning of AdLab, students would rely on the instructor to help them out and this was often limited to a sort of "take a ticket for instructor time" setup. By the end of AdLab, students who had developed experimentcentric expertise were now being asked for help and would freely oblige, often spending upwards of 30 minutes helping another group. 


\section{E. Episode 5: Social interactions}

Episodes 1 and 2 focused on the "brief me on the experiment" interaction. This was not the only type of interaction that occurred in the AdLab community of practice. Social interactions were also infrequent to begin with but, as with the previous interactions, became more prevalent once the classroom community had negotiated its norms in relation to social interactions. These interactions ranged from the frivolity of cracking jokes to discussions about topics that would be considered off topic but are often inspired by some aspect of the experiment they are engaged in.

In the following episode Matt and Larry are no longer working in the same group but are, for their corresponding experiments, working in close proximity. It is week 9 and Matt has just completed the experiment that Larry is now working on, microwave optics. In this experiment students are expected to demonstrate the wave nature of light in a number of interference, diffraction, and reflection experiments using microwaves. Matt is currently working on scanning tunneling microscope with his group. This episode demonstrates the camaraderie and social aspect of the classroom community of practice that evolved over time.

Matt (concerned tone) Are the microwaves on?

Larry Well they are going this way (indicates the direction he thinks the waves are going).

Matt They're reflecting onto your crotch.

Larry (laughs) Oh yeah! You're right. Oops! I was like ... I'll make sure that Percy and Matt are not in the line of fire. I forgot to make sure I wasn't in the line of fire. Thanks for your concern about my crotch.

\section{Matt (smiling) You're welcome.}

This episode has two components to it. First, it has an obvious component of Matt playing Larry's setup of the experimental equipment for humor by referencing the rays reflecting on his crotch. Humor can have a large effect on community building [56] and is a form of discourse that can emphasize membership. The understanding of a joke can illustrate that "you are one of us," just as missing the humor behind a joke can result in alienation from a community. This is a joke situated within the AdLab community and the presence of such social interactions indicates the development of a classroom community of practice.

The second component is that this interaction is able to occur because of the structural features of the classroom all in the room together, long and difficult experiments, and same experiments at different times. If Matt had not completed the microwave optics lab previously, was not in the room with Larry, had not built up the content expertise, or had the time to pay attention to what Larry was doing, then he may not have had the ability to say anything about Larry's setup. Incidentally, there is an affective element to this interaction as well. Matt is genuinely concerned that Larry is doing something wrong that might have negative effects on Larry in some capacity, even though it is communicated through humor. It indicates an element of the affective nature of communities in that members will look out for their fellow members. This whole episode also is one of many examples found within the data set of community involvement growing between groups.

\section{F. Episode 6: AdLab-based discourse}

As mentioned in episode 5 and in the section on community of practice, a big part of being integrated into a community is to begin to appropriate the discourse of the community. If the misinterpretation of jokes can lead to alienation, so can the inability to communicate in the language of the community. The appropriation of discourse is an element of all communities that develop, and the following episode is included to provide evidence that, like all communities of practice, an AdLab-specific discourse developed in the AdLab environment. The following episode occurs as Sally, Danny, and Mike are on their second day of working with the NMR spectrometer. The NMR has multiple possible experiments designed for use with the equipment, some of which are reliant on obtaining the free-induction decay (FID) signal on an oscilloscope. Oliver, Toby, and Laura had previously completed the NMR experiment and are working on the Millikan oil drop experiment, which is not located next to (but is within sight of) the NMR setup. Laura had just borrowed a ruler from Sally. While returning it, Laura relays a message from Oliver to Sally's group.

Laura Thanks Sally. Oliver says nice FID signal.

Sally (laughs) Thanks.

Although brief, this example gives a great sense of the development of the AdLab classroom community of practice, as by this time period of the classroom community, experiment-specific discourse has become ubiquitous among those who have carried out certain experiments. It was not just "nice signal," it was "nice 'FID' signal." The students began to develop and appropriate the language of the community and use it within the classroom.

Another element of classroom community development that is in evidence in this exchange is the fact that Oliver feels comfortable to comment on another group's experiment and how well they are doing. The groups moved from a beginning point where they were insulated groups occasionally discussing how hard an experiment was to the point where they are freely discussing, socializing, and evaluating each other's work on a regular basis.

Episodes 1-6 have been presented above to demonstrate how the structural features and an instructional choice on 
behalf of the instructor encouraged intergroup cooperation and collaboration that has helped to develop a classroom community in the AdLab course with enculturation elements. The episodes emphasize the importance of these structural features and how they are connected to the development of specific elements of our classroom community of practice like the negotiation of norms or distributed expertise. The above episodes are a tiny minority of episodes that could have been chosen as evidence of the development of a classroom community with these enculturation elements. In the next section we present quantitative evidence of how often groups interacted as further evidence of the many central participant, level of community involvement, and collaboration elements of the classroom community.

\section{G. Quantitative analysis of community talk}

Table I presents the percentage of laboratory time the three groups observed spent interacting with another group in the laboratory environment at two different time periods. "Initial" refers to each group's percentage interactions with other groups during their second experiment of the semester. An experiment typically lasted four classroom sessions over a two week period, which would be approximately 12 hours of class time. "Final" is the percentage of interactions with other groups for their second-to-last experiment of the semester. By the penultimate experiment of the semester, group A has remained static in its membership while groups $\mathrm{B}$ and $\mathrm{C}$ changed members after their third experiment, as indicated in Fig. 1. An intergroup interaction was coded in one of three ways. The first was if a member of another group came over to the group being observed and interacted with them. The second was if a member of the group being observed left that group to go interact with another group. The third was if groups initiated a conversation or joined a conversation with another group while being physically adjacent to their experimental setup. In the counting of interactions we did not distinguish the kind of interaction (i.e., topic of conversation) as social interactions can be an important element of building a classroom community. We can stipulate that the majority of interactions were classroom related and that the students had no negative interactions such as fist fights or shouting matches. The general tenure of the room was positive and supportive. The total time spent interacting with other groups by the three previously described methods was combined to calculate the total amount of time spent interacting with other groups.

The results indicate that the difference in time spent interacting with other groups between the two time periods "initial" and "final" for all three groups is substantially different. The amount of interactions that each group had with other groups at the start of the semester are substantially less than the amount of interactions at the end of the semester. The consistency in the difference between amount of time interacting with other groups between the "initial" and "final" time periods across all groups allows a claim that more classroom discourse was occurring between groups by the end of the semester. This is a compelling argument that a classroom community of practice did develop over time in the advanced laboratory community. There are differences between the increase in interactions between groups, especially in the case of group B, which as a group did not increase in the amount of time they interacted with other groups as greatly as the other two groups. Although group membership and personality may account for the difference, it is worth noting that group B's final experiment was the NMR setup. The NMR experiment was new to the advanced laboratory learning environment, and the groups that had completed the experiment prior to group B all struggled with it. This resulted in the instructor spending more time with the group than was typical and preempting problems that the group may have sought solutions for from prior groups. Overall, though, these results demonstrate that all three groups became further involved in the classroom community as the semester progressed.

\section{INTERVIEW REFLECTIONS ON CLASSROOM COMMUNITY DEVELOPMENT}

As part of the longitudinal study examining how upperlevel physics students develop an identity as a physicist, we conducted semistructured interviews on a regular basis for the majority of this group of students. One of these sets of interviews was conducted at the 10 week point of the AdLab semester. As part of this interview we inquired about the students' experiences in AdLab. An important theme to emerge from the interview data is that the students also noticed several of the structural features that promote community development. In the following sections we discuss extracts from the interviews that pertain to specific structural or community building factors.

\section{A. Extract 1: Paucity of instructor time}

In extract 1 the interviewer asks Matt what he thought of the approach to instruction that was taken in the AdLab environment. From observations by the investigators in AdLab sessions, they noticed that in the beginning of the semester there was often a queue for the instructor's attention but that this became a less prominent feature of the classroom as time passed. We wanted to know if the students were aware of this and how they felt about a perhaps perceived lack of access to the instructor.

Matt It was pretty well taught but there was a lot of people in there so we couldn't get a lot of one on one time, when we needed help. So, two of our experiments, the first two, we were the first group doing so we couldn't ask anyone else 
about them, but the other ones, when we couldn't consult with (Instructor), we went to the people that had already done that experiment and they were usually able to figure what it is we were missing or what went wrong when we were setting up like that.

Matt specifically references the amount of people in the room and the lack of one-on-one time when help was required. This is Matt noticing the structural feature of paucity of instructor time and indicating that this was something he found problematic at first. This was resolved once the other groups in the lab and himself had built up experiment-specific expertise and began to consult with each other. The consulting with each other and experimentspecific expertise are further evidence of the structural features all in the room together, long and difficult experiments, and same experiments at different times although Matt is not being as explicit about the last three features.

\section{B. Extract 2: Long and difficult experiments}

Extract 2 is taken from an interview conducted near the end of the AdLab semester and covers all four of the structural features again. In this case, though, Toby's reflections refer more explicitly to the long and difficult experiments aspect of the structure. Toby is answering the same question as Matt did in extract 1 in regards to what he thought of the approach to instruction and describes spending time working with other students. The interviewer follows up by asking Toby specifically about collaboration and working with other students. Toby describes several instances of his group or himself both providing help and receiving help from several different groups.

Int How did you collaborate with the other people and what did you get from the other people in advanced lab?

Toby If we ever had a problem, like we had a problem, with the Zeeman experiment. We couldn't quite figure out how we were supposed to set it up, so we went to Mike, asked him, and he showed us how he did it. For NMR (referring to the group currently doing that experiment), they weren't quite sure what they were doing so they had Oliver and me come over. Mainly Oliver, but I helped a little bit. We did the "E/M Hoag" [experiment]. For the "E/M Hoag" we had to derive the equation we needed and we went to eh Larry and Roy and we were able to look at their work and see what they did and once we saw were they started, it wasn't particularly hard to get it. So, we basically drew on their experience. Everyone seemed to draw on the experience of the experiments everyone else had when starting.

Toby's description of the give and take of assistance between groups over several experiments indicates the growth of a classroom community of practice. The paucity of instructor time is referenced in Toby's description of going to another group when a problem arose as opposed to the instructor. The long and difficult experiments is indicated by Toby seeking out other groups to help with equipment setup or derivations and the other groups had both the expertise and the time to help them out. Reciprocally, Toby had the time to help other groups when they had similar problems. Doing the same experiments at different times allows the experiment-specific expertise to develop.

\section{Extract 3: Community Development}

A portion of each interview was aimed at examining how students perceived what they were getting out of their advanced laboratory experiences. For the most part, this involved students describing how the experience had helped them understand the material, but some questions were directed at asking what they thought about particular elements of the course design. In extract 3 the interviewer asks Tom what he thought was the purpose of the presentations that each student had to perform once a semester.

Int So what do you think the point is behind the presentations?

Tom So, we have to present things in real life, we have to talk to people ... it also strengthens our knowledge of the experiments and builds a community in the class, you get to talk to other people.

Tom thinks that the presentations are a part of the course in order to foster real-world experiences or, in other words, develop some authentic physicist practices. Students identifying aspects of the course that they perceived as contributing to their preparedness for future endeavors in the interviews was common. It was also common that students made reference to collaborating or working with other groups as indicated in extracts 2 and 3 as Tom does by identifying explicitly that the goal of the presentation activity is community development driven.

\section{Extract 4: Development over time}

As with extracts 1 and 2, part of the semistructured interview focused on collaboration with other groups and students. In the description of bounded communities of practice, earlier in the paper we described that they did not just occur when you put a group of people together in a room. A development process has to occur and norms have 
to be negotiated. In extract 4 , Tom reflects that he did not ask other groups about labs in the beginning but that this changed over time.

Int So did you ask other people about labs often? Tom At the start not really. I kind of just kept to my group, except, well with the other groups that I knew I made jokes with, I'd hear things and just make jokes. I'm doing it more now, other people are talking to me as well about labs.

It was indicated in Sec. IV that this process of isolated groups becoming more interactive over time was observed in both the quantitative and qualitative observational results. Tom reflecting on the process is further evidence that the classroom community developed over time. The next section will also reflect on interview data but will focus on the other element of the AdLab being classified as a crucible course: the substantial change in ADK.

All of the above extracts provide further evidence that the enculturation elements developed within the classroom community over time and that students were aware of some of these elements.

\section{E. Students' descriptions of AdLab as a jump in accountable disciplinary knowledge}

Another feature of the AdLab learning environment is that there is a quite observable change in ADK from the previous courses that the students would have taken. As discussed previously, ADK is "what counts" as doing physics. Evidence of an ADK jump in AdLab is very striking in students' descriptions of the course after participating in it for one semester.

Tom The labs are more complex and more interesting. A lot less hand holding. They're more enjoyable and they are actually looking at phenomena that I am interested in ... its more about us discovering the phenomena...it feels like more of a professional setting than most of my other courses.

Matt We have been investigating actual atomic structures or how to find the mass of an electron ... previous labs would be a lot more cut and dry. Here's the procedure. Follow it. You'll get the results. Easily, these ones were more of, here's the procedure. Most of it usually. Follow it and try and understand what's going on cause if you don't you won't know if what you're getting is any good ...the real feeling of being a physicist was trying to understand all that stuff that we get from it.

Laura I really had to do a lot of work on my own and I wasn't really expecting that ...I thought maybe the lab write ups would be a little bit more prescribed and not so quite ... it's kind of like, these are your objectives, this is how the machine works, do it, and thats good.

Toby Yeah, the subject matter itself changed but that's to be expected for a higher level class ... obviously they are trying to get you to really think about the subject matter. To understand the subject matter at a deeper level than just in EP labs. They want you to see it happen in advanced lab. They want you to see it happen and understand why it's happening by figuring it out yourself rather than being told. I mean we don't want to create people who can just rattle of equations without understanding what those equations really mean. You want people who actually understand what those equations really mean ...this time we have a lot more freedom in the time that it takes to do it. You know we have some constraints because the other groups have to use the equipment as well, but we can come in on our own and do it. The freedom was nice even if it was the result of having more work.

Several of the students perceive that a lot of what they were doing in the AdLab environment and how they participated in it were more like authentic practices of physicists. The students also clearly perceived a jump in the level of the material and what was expected of them in the AdLab classroom. Changes in expectations are obvious from students noting that there was a lot more freedom, the labs were less prescribed, and that they were expected to gain an understanding of the material and not just get a set of data.

\section{RELATING COMMUNITIES OF PRACTICE TO ACCOUNTABLE DISCIPLINARY KNOWLEDGE: CRUCIBLE COURSES}

The combination of quantitative and qualitative results presented in this paper clearly indicate that a classroom community of practice developed in the AdLab learning environment with certain enculturation elements. It is also obvious from the students' reflections on the course that there was a substantial change in ADK from their previous experiences due to substantial changes in the structural and programmatic features of the AdLab learning environment. This combination of change in ADK along with an emphasis on enculturation elements resulted in students being offered the opportunity to accelerate their own trajectory to being more of a central participant of the physicists' community of practice. This emphasis on enculturation from both ADK and structure has resulted 
in us labeling the AdLab course as a possible "crucible course."

We describe crucible courses as the first courses in which students work on difficult physics problems surrounded primarily by other physics students, where they are treated by their professors as junior physicists, and they take on identities as part of the broader community of physics undergrads. In our prior work, we identified crucible courses as those associated with large changes in ADK and developments of physics identity. Both students [57] and researchers [54] seem to know these courses "when they see them" [58]. The courses are typically intermediate level (taken by sophomores or juniors) and are among the first courses populated predominately by physics majors and minors. They have smaller enrollments and foster a greater sense of community within the class. They may be theory courses or laboratory courses, but in either case the expectations of students and their perceptions of the stakes are substantially higher than in previous courses. This is a working definition, and we intend to further investigate what the key elements of a crucible course are. We believe an emphasis on enculturation is a key feature of a crucible course.

To discuss this enculturation process further, we must first examine communities of practice and how we interpret where they fit into the college environment. In alignment with previous researchers [24-26,35,38], we believe it is applicable to view the classroom community as a community of practice. If that is the case, as a student you will occupy many communities of practice concurrently within the college environment while also being a member of several other communities outside of the college context. In fact, the majority of students' waking hours during their time in college will not be spent in the classroom [10]. The combination of these memberships to a variety of communities of practice will all have influences on each other and can help in the development of a physics identity in both obvious and less obvious ways.

Students are on trajectories to developing an identity as a physicist when they enter a physics classroom. Once they enter a physics classroom they are developing a relationship with physics that may turn into a physics identity. They may not intend on becoming a physicist, it might not even be their major, but when they enter a physics classroom they engage in a variation of the practices of becoming a physicist. That is the nature of the a classroom being a community of practice, and so, in essence, any physics classroom is a subcommunity of the broader community of physics undergrads and the community of practicing physicists.

\section{DISCUSSION}

All classroom communities of practice are different, and these differences may be trivial or may be extensive. Different classroom communities offer different levels of exposure to the authentic expectations, practices, content knowledge, and discourses of the discipline of physics. Therefore, we argue that each classroom community can result in students progressing towards being a central member of the community of practicing physicists at different accelerations. To clarify, the classrooms would offer the opportunity, but it is up to the students to participate either peripherally or centrally.

A student can have a bad experience in the classroom, such as having a negative reaction to a student-centered learning environment. In this case, we would expect them to participate peripherally and not become a central member of the classroom. We would postulate that students who are participating in a peripheral manner may still be enculturated to some extent into the practicing physicists' community. We would argue that they are still being exposed to new physics content. However, this would be expected to be a relatively minor progression or none at all. We would also expect that this may affect their interest and feelings towards the subject of physics and may affect retention and persistence.

From a positive perspective, we believe the AdLab classroom is an example of a community of practice that offers the opportunity to have an accelerated trajectory towards being a central participant of the community of practicing physicists. The AdLab introduces students to the authentic expectations, practices, content knowledge, and discourses of the practicing physicists' community. This is achieved by having the students collaborating as a group and with other groups on long and difficult physics experiments. These experiments are more modern in setting in an environment that echoes what students might perceive as a research environment. Being a central participant in this environment will accelerate one's trajectory to being a more central participant of the community of practicing physicists.

In the Introduction, we discussed how the development of professional identity is a key part of student development. The AdLab learning community offers an opportunity to develop authentic elements of the identity of a practicing physicist. It also offers a simulation of what practicing in the community of physicists might be like to experience. Both the authentic practice and community simulation are positive experiences that can aid in students' persistence in a discipline [2-5]. It has been argued that one of the most important contributions to developing a subjectspecific identity is recognition both by peers and by the community in which students wish to become a central member [59]. A community that has many similarities to that of a professional research environment provides the opportunity for students to recognize each other as more authentic physicists than before.

Although we argue for the positives of classrooms that provide accelerated trajectories, we do not think that all classroom communities of practice should offer 
opportunities of accelerated trajectories. An accelerated trajectory classroom in introductory physics would be inappropriate. It has been indicated [23] that there are already great shifts being expected of students in introductory classes as teachers try to move students away from being socialized to memorize, practice, and recite and move towards being comfortable with constructivist and social constructivist perspectives. There might be too much of a substantial change in ADK for students to deal with among a period of already extensive change. Also, the norms of college can be very different from the norms of school and again the norms of actual practitioners of physics.

Using the communities of practice framework with the idea of of ADK helps us to examine what students are learning and why from a cultural angle. This relationship is a useful frame from which to examine learning environments in the future. The relationship and the enculturation elements might also inform instructors who are attempting to assess the more "hidden curriculum" learning goals of the learning environments that they are designing. This is especially true for advanced lab classes nationwide that are similar in structure to the one described in this study.

We have argued that AdLab develops into this classroom community of practice very effectively due to the factors of paucity of instructor time, all in the room together, long and difficult experiments, do some of the same experiments at different times, and instructor supports the development of a classroom community of practice. Of the above claims, all of them have been discussed extensively in the results except for all in the room together. This claim comes from the assertion that, in the previous semester, some of the same students took the modern laboratory course. This course is set up so that each group of students attempted the same experiment each week and so no classroom community of practice could develop, except among each separate group of two or three students. When asked in interviews whether they had discussed the laboratory they were trying to complete with other members of the modern laboratory class, the answer was typically no, although they often did work with their group outside of class.

As mentioned previously, the development of a community in community of practice literature is not commonly discussed, but to us is a key feature of bounded communities of learning. A community of practice in the classroom does not form on the condition of putting students in a room together, although it may result in one eventually. In our case, the classroom community of practice developed that had several elements: classroom norms and expectations, distributed expertise, community involvement, many central players, and the instructor is not the sole mediator. We argue that these elements developed due to the presence of several structural features of the classroom we have emphasized. We also believe that this is due to the instructor's choice to emphasize collaboration. These elements are an important part of the accelerated trajectory available for students to take due to the AdLab course.

The emphasis of this paper is not focused on the instructor. This should not be interpreted as the instructor being unimportant to the AdLab laboratory learning environment. Nor should it be interpreted that the instructor had no role in the development of the classroom community. There are limitations placed on the instructor by the learning environment that result in such structural features as "paucity of instructor time." Another limitation would be that the experiments had to be done in a series, though the instructor did make structural choices, as well. The decision to let students choose their next experiment resulted in a lot of the "shopping around" interactions that occurred between groups that resulted in community building. Episode 3 also highlights a move that the instructor made to encourage a group to seek the expertise of another group.

We would argue that the enculturation elements of the classroom community be viewed as an instructional guide to developing an accelerated trajectory classroom. In a student-centered classroom, all of these elements should be considered important to developing an effective learning community. The structural features highlighted in this paper that resulted in the development of these enculturation elements is in no way an exhaustive list. An important omission to this list is the role of the instructor. The instructor has to be aware of the possible enculturation elements that could develop in their learning environment and encourage them to grow. There may be additional structural elements that could result in the growth of a classroom community. However, they are not investigatable in the learning environment in which this study is set.

The classroom community did not start with the enculturation elements. Students' ways of participating change as they learn the norms and practices of the classroom community of practice, which includes developing a shared discourse with their fellow community members of students and instructors [60]. The students also have to figure out the boundary constraints [14] of this new community of practice due to it being a bounded community. Norming is one of the five stages of group development [61] and, although not necessarily relatable to the communities of practice theory, it does indicate that the classroom has to go through some development before it becomes the finalized version of the learning community. We believe for the AdLab classroom the features previously mentioned are the reason why it developed into a classroom community with enculturation elements and the majority (if not all) of the students participating centrally.

A big change in ADK from course to course can be difficult for students, as often what they think doing physics means has changed from what it has meant in the past. It could be argued that the classroom community of practice developing is a support mechanism for the students in order 
to deal with the change in ADK. A big change in ADK without a classroom community developing could result in greater losses, in retention, and persistence as student's struggle to deal with the changes in norms and expectations. Added to this is that cultural practices of professional scientists are always adapted to fit the realities of the classroom and to suit the teacher's values or goals $[36,62]$. When designing curricula or courses, careful consideration should be given to the expectations, practices, content knowledge, and discourses of the community of physicists that are being incorporated into the design. A realization must be made that what we ask of the students is not just different content, but a substantial change in that content. Attached to this change is a different set of norms and expectations.

Adding structural and instructional features to a course that encourages the development of an effective classroom community of practice may be one way of equipping students to deal with such transitions.

\section{CONCLUSION}

The AdLab community of practice was identified as a classroom community that provides the opportunity to accelerate a student's trajectory to becoming a member of the community of practicing physicists. Students are more likely to persist with a discipline if they feel as if they are participating in its professional community and if they develop a subject-specific identity. A learning environment with an accelerated trajectory can provide students with both of these aspects at an accelerated rate. This is due to enculturation elements in this environment developing quickly due to paucity of instructor time, all in the room together, long and difficult experiments, do some of the same experiments at different times, and instructor encourages the sharing and codevelopment of knowledge and understanding. This paper argues that learning environments can be structured to provide students with the opportunity to become more central members of the community of practicing physicists.

This paper is supported by the Kansas State University Physics Department. We thank the instructor of the laboratory for her access to the AdLab environment and for sharing her time and contributing to discussions with us. We also thank the students for participating in and contributing to this study.
[1] O. Pierrakos, T. K. Beam, J. Constantz, A. Johri, and R. Anderson, On the development of a professional identity: Engineering persistors vs. engineering switchers, in Proceedings of the 2009 IEEE Frontiers in Education Conference (IEEE Press, Piscataway, NJ, 2009), Vol. 39, pp. 599-604.

[2] C. A. Barton and K. Yang, The culture of power and science education: Learning from Miguel, J. Res. Sci. Teach. 37, 871 (2000).

[3] C.A. Chinn and B.A. Malhotra, Epistemologically authentic inquiry in schools: A theoretical framework for evaluating inquiry tasks, Sci. Educ. 86, 175 (2002).

[4] A. Cleaves, The formation of science choices in secondary school, Int. J. Sci. Educ. 27, 471 (2005).

[5] M. C. Shanahan, Playing the role of a science student: Exploring factors and patterns in science student identity formation, Ph.D. thesis, University of Toronto, 2007.

[6] A.-b. B. A. Hunter, S. L. S. Laursen, and E. Seymour, Becoming a scientist: The role of undergraduate research in students' cognitive, personal, and professional development, Sci. Educ. 91, 36 (2007).

[7] I. D. Bonnar, Not as cool as fighter pilots, Ph.D. thesis, University of Stirling, 2007.

[8] J. Lave and E. Wenger, Situated Learning: Legitimate Peripheral Participation (Cambridge University Press, Cambridge, England, 1991).

[9] H. Del-Castillo, P. Lacasa, and A. B. Garcia-Varela, Literacies through media: Identity and discourse in the process of constructing a web site, Int. J. Educ. Res. 39, 885 (2003).

[10] S. Li, Learning in a physics classroom community: Physics learning identity construct development, measurement and validation, Ph.D. thesis, Oregon State University, 2011.

[11] A. T. Danielsson, The gendered doing of physics: A conceptual framework and its application for exploring undergraduate physics students' identity formation in relation to laboratory work, Ph.D. thesis, Uppsala Universitet, 2007.

[12] E. Wenger, Communities of Practice: Learning, Meaning, and Identity (Cambridge University Press, Cambridge, England, 1998).

[13] E. Coakes and S. Clark, Communities of Practice: The Concept in Information and Knowledge Management (IRM Press, Hershey, PA, 2006),

[14] S. Barab, M. Barnett, and K. Squire, Developing an empirical account of a community of practice: Characterizing the essential tensions, J. Learn. Sci. 11, 489 (2002).

[15] J. Nespor, Knowledge in Motion: Space, Time and Curriculum in Undergraduate Physics and Management (Falmer Press, Washington, DC, 1994).

[16] J. Charney, C. Hmelo-Silver, W. Sofer, L. Neigeborn, S. Coletta, and M. Nemeroff, Cognitive apprenticeship in science through immersion in laboratory practices, Int. J. Sci. Educ. 29, 195 (2007). 
[17] P. L. Hsu and W. M. Roth, From a sense of stereotypically foreign to belonging in a science community: Ways of experiential descriptions about high school students' science internship, Res. Sci. Educ. 40, 291 (2010).

[18] D. Lopatto, Science in Solution: The Impact of Undergraduate Research on Student Learning (Research Corporation for Science Advancement, Tucson, AZ, 2009), 1st ed.

[19] M. Furman and A. Calabrese Barton, Capturing urban student voices in the creation of a science minidocumentary, J. Res. Sci. Teach. 43, 667 (2006).

[20] P. R. Aschbacher, E. Li, and E. J. Roth, Is science me? High school students' identities, participation and aspirations in science, engineering, and medicine, J. Res. Sci. Teach. 47, 564 (2010).

[21] G. S. Aikenhead, Science education: Border crossing into the subculture of science, Stud. Sci. Educ. 27, 1 (1996).

[22] V. B. Costa, When science is "another world": Relationships between worlds of family, friends, school, and science, Sci. Educ. 3, 79 (1995).

[23] R. Borasi, M. Siegel, J. Fonzi, and C. F. Smith, Using transactional reading strategies to support sense-making and discussion in mathematics classrooms: An exploratory study, J. Res. Math. Educ. 29, 275 (1998).

[24] A. H. Schoenfeld, in Learning to Think Mathematically: Problem Solving, Metacognition, and Sense-Making in Mathematics, edited by D. Grouws, Handbook for Research on Mathematics Teaching and Learning (MacMillan, New York, 1992), Chap. 15, pp. 334-370.

[25] J. L. Lemke, Talking Science: Language, Learning, and Values (Ablex Publishing, Norwood, NJ, 1990).

[26] L. K. L. Berland, Explaining variation in how classroom communities adapt the practice of scientific argumentation, J. Learn. Sci. 20, 625 (2011).

[27] R. Nathan, My Freshman Year; What a Professor Learned By Becoming a Student (Cornell University Press, Ithaca, NY, 2005).

[28] P. Cobb, M. Stephan, K. McClain, and K. Gravemeijer, Participating in classroom mathematical practices, J. Learn. Sci. 10, 113 (2001).

[29] B. Rogoff, E. Matusov, and C. White, The Handbook of Education and Human Development: New Models of Learning, Teaching and Schooling. (Blackwell, Cambridge, MA, 1996), Chap. 23, pp. 6-42.

[30] R. M. Goertzen, E. Brewe, and L. Kramer, Transforming participation: A case study of an introductory physics student in a modeling instruction class, in Proceedings of the Tenth Annual College of Education and Graduate Network Research Conference (COERC 2011), edited by Maria S. Plakhotnik, Sarah M. Nielsen, and Debra M. Pane (College of Education, Florida International University, Miami, FL, 2011).

[31] M. Lampert, When the problem is not the question and the solution is not the answer: Mathematical knowing and teaching, Am. Educ. Res. J. 27, 29 (1990).

[32] R. Stevens, K. O'Connor, L. Garrison, A. Jocuns, and D. M. Amos, Becoming an engineer: Toward a three dimensional view of engineering learning, J. Eng. Educ. 97, 355 (2008),
[33] K. A. Bruffee, Collaborative Learning: Higher Education, Interdependence, and the Authority of Knowledge (Johns Hopkins University Press, Baltimore, MD, 1997).

[34] K. S. Cockrell, J. A. Hughes-Caplow, and J. F. Donaldson, A context for learning: Collaborative groups in the problem-based learning environment, Rev. High. Educ. 23, 347 (2000).

[35] R. A. Duschl and J. Osborne, Establishing the norms of scientific argumentation in classrooms, Stud. Sci. Educ. 38, 39 (2002).

[36] K. Squire, J. G. MaKinister, M. Barnett, A. L. Luehmann, and S. Barab, Designed curriculum and local culture: Acknowledging the primacy of classroom culture, Sci. Educ. 87, 468 (2003).

[37] K. Hogan and C. Corey, Viewing classrooms as cultural contexts for fostering scientific literacy, Anthrop. Educ. Q. 32, 214 (2001).

[38] D. Demaree and S. Li, Promoting productive communities of practice: An instructors perspective, AIP Conf. Proc. 1179, 125 (2009).

[39] S. Pirie, Working toward a design for qualitative research, J. Res. Math. Educ. 9, 79(1997).

[40] H. Garfinkel, Studies in Ethnomethodology (Prentice-Hall, Englewood Cliffs, NJ, 1967).

[41] G. Marcus, Ethnography through Thick and Thin (Princeton University Press, Princeton, NJ, 1998),

[42] B. A. Brown, Discursive identity: Assimilation into the culture of science and its implications for minority students, J. Res. Sci. Teach. 41, 810 (2004).

[43] A. A. Collins, D. Joseph, and K. Bielaczyc, Design research: Theoretical and methodological issues, J. Learn. Sci. 13, 15 (2004).

[44] P. Ernest, Social Constructivism as a Philosophy of Mathematics (University of New York Press, New York, 1997).

[45] R. M. Emerson, R. I. Fretz, and L. L. Shaw, Writing Ethnographic Field Notes (University Of Chicago Press, Chicago, 1993).

[46] J. M. Case and G. Light, Emerging methodologies in engineering education research, J. Eng. Educ. 100, 186 (2011).

[47] Z. Hazari, G. Potvin, R. H. Tai, and J. Almarode, For the love of learning science: Connecting learning orientation and career productivity in physics and chemistry, Phys. Rev. ST Phys. Educ. Res. 6, 010107 (2010).

[48] E. F. Redish and D. Hammer, Reinventing college physics for biologists: Explicating an epistemological curriculum, Am. J. Phys. 77, 629 (2009).

[49] S. Sandi-Urena, M. M. Cooper, and T. A. Gatlin, Graduate teaching assistants' epistemological and metacognitive development, Chem. Educ. Res. Pract. 12, 92 (2011).

[50] A. Brown, Teacher Education Crossing Borders: Cultures, Contexts, Communities and Curriculum (Australian Teacher Education Association, Albury, 2009), pp. 1-12.

[51] J. Biggs, The role of metalearning in study processes, Br. J. Educ. Psychol. 55, 185 (1985).

[52] G. J. Kelly and T. Crawford, An ethnographic investigation of the discourse processes of school science, Sci. Educ. 81, 533 (1997). 
[53] J. Green and C. Wallat, Ethnography and Language in Educational Settings (Ablex, Norwood, NJ, 1981).

[54] E. C. Sayre and M. C. Wittmann, Physics identity development: A snapshot of the stages of development of upperlevel physics students, Phys. Rev. ST Phys. Educ. Res. 4, 020105 (2008).

[55] P. W. Irving, M. S. Martinuk, and E. C. Sayre, Transitions in students' epistemic framing along two axes, Phys. Rev. ST Phys. Educ. Res. 9, 010111 (2013).

[56] L. Thrysoe, L. Hounsgaard, N. B. Dohn, and L. Wagner, Newly qualified nurses-experiences of interaction with members of a community of practice, Nurse Educ. Today 32, 551 (2012).

[57] P. W. Irving and E. C. Sayre, Physics identity development: A snapshot of the stages of development of upper-level physics students, J. Scholar. Teach. Learn. 13, 68 (2013).
[58] P. Stewart, Jacobellis v Ohio, U.S. Rep. 378, 184 (1964).

[59] Z. Hazari, G. Potvin, R. M. Lock, F. Lung, G. Sonnert, and P. M. Sadler, Factors that affect the physical science career interest of female students: Testing five common hypotheses, Phys. Rev. ST Phys. Educ. Res. 9, 020115 (2013).

[60] K. Bielaczyc and A. Collins, Instructional-Design Theories and Models: A New Paradigm of Instructional Theory (Lawrence Erlbaum, Mahwah, NJ, 1999), Chap. 12, pp. 269-292.

[61] B. W. Tuckman, Developmental sequence in small groups, Psychol. Bull. 63, 384 (1965).

[62] K. Hogan and M. Maglienti, Comparing the epistemological underpinnings of students' and scientists' reasoning about conclusions, J. Res. Sci. Teach. 38, 663 (2001). 